\title{
Electronic health records: an asset or a whole lot of hype?
}

Published at www.cmaj.ca on Jan. 25

$\mathrm{S}$ trikingly different accounts of the importance of electronic health records in improving health outcomes for patients emerged at a national summit on primary health care held in Toronto, Ontario, in January.

According to an executive with the American health care giant Kaiser Permanente, electronic health records can dramatically improve quality of care and patient outcomes.

But the principal investigator of a series of major Canadian studies says there's little or no evidence that health outcomes are improved by the use of electronic health records.

The advantages are enormous, argued Andrew Wiesenthal, associate executive director of the Permanente Federation, who led a five-year project to integrate a US\$4-billion electronic health record system among Kaiser Permanente's 14000 physicians, 165000 employees and 36 hospitals serving 8.7 million patients in numerous states. Wiesenthal said $44 \%$ of Kaiser's 7.2 million adult patients can now access their health records via secure online systems that allow them to book appointments and directly consult with care providers.

It has yielded dramatically more effective nursing and physician care, a $57 \%$ reduction in medical errors and a $31 \%$ reduction in pharmaceutical usage considered high-risk due to drug-drug interactions, Wiesenthal said. Physicians can instantly review errors to identify causes and "make them go away."

But "none of the things we've achieved can be achieved within a fee-for-service health care system," Wiesenthal told delegates to the Canadian Institutes of Health Research Primary Care Summit.

Anne Holbrook, director of the Division of Clinical Pharmacology and Therapeutics at McMaster University in Hamilton, Ontario, offered a vastly different assessment and urged caution.

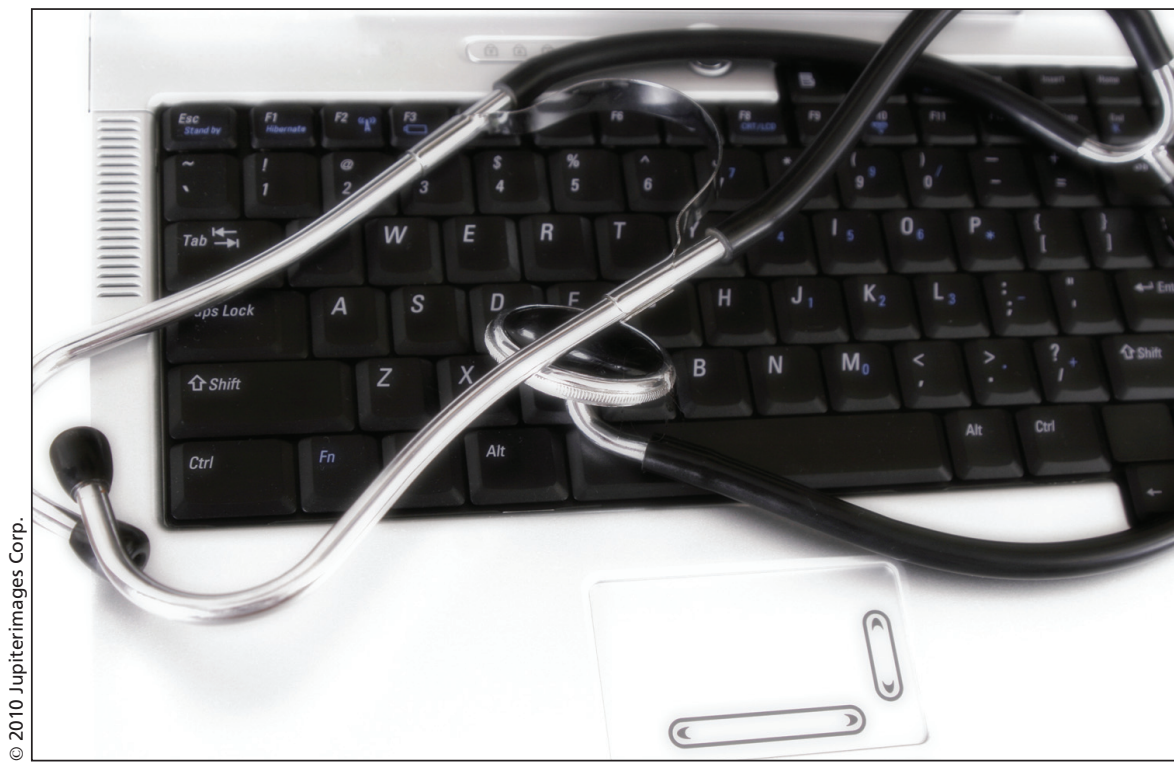

A United States health administrator says that a move to electronic health records by health care giant Kaiser Permanente resulted in a $57 \%$ reduction in medical errors.

Holbrook said her work as principal investigator of COMPETE, a threephase, \$7.3-million study of electronic health records in Canada, indicates that they may have some value, but “there's very little that's been proven. We need high-quality research before we spend more."

And when it comes to patient outcomes, she added, "there is no evidence that EMR [electronic medical records] makes a difference."

The massive financial investments across Canada in systems linking patients and health care providers is being "driven by system needs" and the profit motives of electronic record system vendors, rather than any kind of evidence that such records improve patient outcomes, Holbrook said.

"We have not been able to show from the literature that drug interaction problems improve," Holbrook added. "There's no effect on clinical outcomes, but very impressive effects on processes."

Wiesenthal offered a flatly different view. "The outcomes on diabetes are better. Just better," he said, adding that his firm has data which indicates that 14000 patients tracked over 12 years revealed a remarkable reduction in deaths among people discharged after heart attacks.

That's attributable to superior patient tracking and physician-patient communication resulting from electronic health records, he said. "We get them started right away on risk intervention."

There are no such success stories in Canada, Holbrook countered. "If you get down to the coal face as I do you'll find it far less satisfactory."

Holbrook added that Kaiser's success stories might be ascribed to "their people" but said that Ontario "is not there yet."

Both indicated that differences in research approaches may lie at the root of their differing perspectives on the value of electronic health records.

Holbrook said her COMPETE studies employ traditional methodologies and rely on "consistent evidence from high quality trials." The three-phase study is guided by an advisory board of Canadian academics, a Calgary, Alberta, family physician and an executive from Merck Frosst Canada. 
Wiesenthal's data is drawn from internal, unpublished studies based on information generated by one of the world's largest fully operational electronic health record systems. "We're not publishing randomized control trial results," he said.

But that may be about to change,
Wiesenthal suggested. With Kaiser's system currently yielding three terabytes of data per month, researchers, particularly geneticists, are "salivating," he said. "This is real data based on patients as opposed to estimates. There's no doubt that EMRs [electronic medical records] can improve care. We're seeing an absolute ferment of innovation about what to do within our system to improve care." - Paul Christopher Webster, Toronto, Ont.

DOI:10.1503/cmaj.109-3164 